\title{
Robotic Process Automation (RPA): Process prioritization using Cognitive Complexity matrix
}

\author{
Arunoday Jaju1, Dr. Prashant Bharge ${ }^{2}$ \\ ${ }^{1}$ Symbiosis Institute of Operations Management, Nashik, Symbiosis International (Deemed University), Pune, India \\ ${ }^{2}$ Professor, Symbiosis Institute of Operations Management, Nashik, Symbiosis International (Deemed University), Pune, India
}

\begin{abstract}
The process automation using robotic processes automation (RPA) has been witnessing an increasing trend of interest in recent days. However, when it comes to selection of processes for automation, among various factors process complexity is not given enough weightage. Also there are fewer researches regarding process selection and the factors impacting this decision. This research gives a methodology for selecting processes based on the complexity so that the organization can implement RPA with the optimum benefits. With this approach we can prioritize the processes in order to gain the maximum profit from the automation. This approach will also segregate the processes in which RPA automation will not result into significant amount of benefit.
\end{abstract}

Article Received: 10 August 2020, Revised: 25 October 2020, Accepted: 18 November 2020

\section{Introduction}

As the term Robotic Process Automation(RPA) suggests, robots working on some processes and doing the human tasks, it is actually a software automation solution where bots sits on top of the legacy IT systems and mimic human activities. It is a technology used in automation of rules based, repeated and labour intensive processes. Using RPA saves a huge cost and time leading to shorter turnaround time for process execution, freeing up resources from their regular job and utilizing this time in a process where human mind is needed.

With globalization, and technologies acting as enabler to ease businesses, the complexity of processes has increased drastically. To maintain complex processes itself has become a complex task. Measuring a process complexity can be a huge challenge. It's important that we use the right parameters to measure the process complexity. There are various complexity measurement methods for business processes and their advantages and disadvantages have been discussed by various researchers. We will refer to the cognitive complexity matrix in this research as it provides the most accurate picture of complexity of a process.

Implementing RPA in an organization requires a lot of background work. To activate the maximum gain and a full proof implementation it's important to create a process pipeline, a queue, which contains the processes which would undergo RPA implementation in an ordered manner. Currently we are having methodologies to decide this pipeline, but, we believe, one factor is not given enough importance in this process, i.e. process complexity. In this paper we will be looking at how we can leverage the cognitive complexity matrix to measure the process complexity and how this can further be utilized to further refine the process pipeline for RPA.

\section{Research Methodology}

First proceedings of the research paper were started by developing a thorough understanding of robotic process automation as a technology and its usage as a platform technology for automating the rules based processes. An in depth literature review has been conducted using existing resources in terms of various published researches from quality journals as well as other online resources like videos, tutorials etc. At the same time understanding of processes and their complexities has been developed to understand the challenges faced while dealing with complex processes. Contemporary other methods were explored to find a relevant parameter to form a matrix and compare the processes among themselves, so that the processes can be prioritized on the basis of optimizing the overall benefit caused to the organization.

Once the link between process complexity and the benefits(in terms of cost) achieved by their automation has been established, the processes are then mapped into a value vs complexity matrix. 
Once the matrix is achieved the below questions are answered for the automation pipeline.

- Which processes should be picked first for the RPA implementation?

- Which processes should be avoided for automation considering the overall investment and the return on investment?

- Selection of which processes for automation would be loss making decision?

- For which processes another approach should also be considered?

With answer to these questions one can take better decisions regarding process selection and their prioritization while implementing RPA into their processes.

\section{Literature Review}

The prime reason why business are striving and existing is profit (monetary or non-monetary). For organisations to achieve this, they try to be unique and distinct from other organisations by gaining competitive advantages in one or more forms. Organisations achieve this by either improvising their current business strategy or technology, that results in shorter lead time, better product quality etc.

One of such technologies, which is gaining popularity nowadays, for producing better results, is RPA - Robotic Process Automation. As the name suggests, Robots doing the processes which are done by human. But these robots aren't like the real robots with some swinging arms and screwing nuts and bolts. In fact, these are robots which are present in form of some software and are doing repetitive, mundane and rules based task just like human does. These robots sit on top of the IT software used by an organization and interact with the user interface of the applications used by them. In simple terms these are the virtual operators doing the same repetitive tasks, which the employees of the organisations do. Thus they eliminate the repetitive nature of the work and gives more time to employees to do brainstorming for ideation, creativity and comparatively more interesting work. Tasks, for which human mind is designed.

- The process of automating business operations to reduce human intervention in activities, that are manual, repetitive, and rule-based.

- RPA enables an organization with the capability to map out a rule bound and well defined process and a software robot can be assigned to execute those tasks and processes.

- The way RPA bots work is very unique. They use the existing applications and their user interface to execute those processes and tasks.

- In many scenario, increase in efficiency, improvement in business productivity and reduction in error rate are achieved with RPA automation. Enhance security and regulatory compliance are few other benefits gained from RPA.

\subsection{Robotic Process Automation}

RPA - Robotic Process Automation is a technology to automate tasks and processes with the help of digital robots. These robots are present in form of software and are doing repetitive, mundane and rules based task just like human does. These robots sit on top of the IT software used by an organization and interact with the user interface of the applications used by them. In simple terms these are the virtual operators doing the same repetitive tasks, which the employees of the organisations do. Thus they eliminate the repetitive nature of the work and gives more time to employees to do brainstorming for ideation, creativity and comparatively more interesting work.

Once organisation decided implementing RPA into their processes, they need to decide the pipeline, an order in which the processes will be automated. Choosing the right pipeline of process is very important as it will decide how much benefit can be realised post RPA implementation. This pipeline is decided considering parameters in table 1 . 


\begin{tabular}{|c|c|}
\hline Criterion & \begin{tabular}{|l|} 
Definition \\
\end{tabular} \\
\hline Degree of rule-based & $\begin{array}{l}\text { This criterion tells us about a business process if its } \\
\text { following rules based if then else decisions or they } \\
\text { have lots of unambiguity in rules. }\end{array}$ \\
\hline Degree of human intervention & $\begin{array}{l}\text { This criterion indicates how many times human } \\
\text { intervention is required in a business process and } \\
\text { how many times human's cognitive decision } \\
\text { making skills are needed to execute that process. }\end{array}$ \\
\hline Structuredness of data & $\begin{array}{l}\text { This criterion tells about the data required and } \\
\text { processed in that business process. If a business } \\
\text { process has structured data requirement it fits better } \\
\text { for the agenda. }\end{array}$ \\
\hline Degree of process digitization & $\begin{array}{l}\text { This criterion refers to till what extent the process } \\
\text { is digitized or is the process still using old school } \\
\text { pen and paper techniques. }\end{array}$ \\
\hline $\begin{array}{l}\text { Degree of similarity of } \\
\text { environments }\end{array}$ & $\begin{array}{l}\text { This criterion refers to different environment i.e. } \\
\text { test, production, development environments of that } \\
\text { business process }\end{array}$ \\
\hline Labor intensity & $\begin{array}{l}\text { This criterion indicates the volume of the process } \\
\text { execution and the head count of labour required to } \\
\text { complete one complete end to end cycle of the } \\
\text { process flow. }\end{array}$ \\
\hline Number of systems involved & $\begin{array}{l}\text { This criterion refers to the count of different IT } \\
\text { systems or application that are needed for end to } \\
\text { end execution of a business process successfully. }\end{array}$ \\
\hline Degree of process maturity & $\begin{array}{l}\text { This criterion indicates how frequently the system } \\
\text { or the application used in a process flow are } \\
\text { changing to accommodate new changes or to } \\
\text { stabilize them. }\end{array}$ \\
\hline $\begin{array}{l}\text { Knowledge about current } \\
\text { process cost }\end{array}$ & $\begin{array}{l}\text { This criterion refers to the awareness of } \\
\text { organization about the different costs associated } \\
\text { with the manual execution of that business process. }\end{array}$ \\
\hline $\begin{array}{l}\begin{array}{l}\text { Number } \\
\text { exceptions }\end{array} \\
\text { of } \quad \text { (known) } \\
\end{array}$ & $\begin{array}{l}\text { This criterion indicates the count of known } \\
\text { exception which can cause interruption in the } \\
\text { normal functional execution of a process. }\end{array}$ \\
\hline $\begin{array}{l}\text { Frequency of system related } \\
\text { changes }\end{array}$ & $\begin{array}{l}\text { This criterion concerns how frequently the system } \\
\text { related changed occurs which changes the user } \\
\text { interface or the functionality of the process. }\end{array}$ \\
\hline
\end{tabular}




\begin{tabular}{|l|l|}
\hline Number of process steps & $\begin{array}{l}\text { This criterion refers to the amount of steps required } \\
\text { to end to end execution of the business process } \\
\text { covering all possible scenarios. }\end{array}$ \\
\hline Risk-proneness & $\begin{array}{l}\text { This criterion refers to the risk associated with the } \\
\text { automation which might lead to interruption in } \\
\text { operation of that business process in case the } \\
\text { automation solution is not developed properly and } \\
\text { correctly considering all associated factors in mind. }\end{array}$ \\
\hline Process standardization & $\begin{array}{l}\text { This criterion defines the standard and common } \\
\text { components or practices followed in both the } \\
\text { process and the organization. }\end{array}$ \\
\hline
\end{tabular}

Table 1. Criterion for processes to be eligible for RPA Automation

In the method of creation of process pipeline, process complexity is not considered. By considering complexity of the process we can eventually look for automating processes which makes economic sense for automating then and thus making financially sound decision.

\subsection{BENEFITS OF RPA IMPLEMENTATION}

- Increased productivity: The robots can increase the overall productivity throughout the process and this can be measured via certain KPIs.

- $\quad$ Better quality: Job done by robots follow the same patterns, each time the process is executed. Also when you deploy multiple bots, they will actually be replica of the same robot. Hence we will not need to train and monitor them and we will get the same quality of work from every robot.

- $\quad$ Faster speed: Bots can complete a task with a $90 \%$ reduction in the overall time consumed as compared to a human doing the same task. With increased process speed, the amount of backlog work also reduces drastically, resulting in quick turnaround time.

- Zero errors: Bots, unlike their human counterparts, don't feel fatigue doing same tasks again and again. Hence bots can work with the same efficiency throughout the time they work. Also they don't make any clerical errors.

Higher Customer satisfaction: Benefits achieved from RPA (Faster TAT, No errors, No quality compromises etc.) results in greater customer satisfaction and customers rely on such organisations.

- Stronger Competitive market position: The improvement, which RPA brings in a platter, gives the organization a competitive edge from other organisations which are not using these technologies.

- Reduced costs: Using RPA results in less operational cost in performing the same task as the bots can reduce the manpower in that particular process drastically and these resources can be used at some other place for more creative jobs.

- Improved compliance: RPA can take care of compliances which are rule based with few exceptions, well documented, require structured input, and repetitive in nature.

- Greater Employee satisfaction from elimination of mundane tasks: Employees can now free themselves from the mundane tasks and utilise the same time in 
creating more innovative solutions to the problems an organisation is facing.

- $\quad$ Reduced costs: Using RPA results in less operational cost in performing the same task as the bots can reduce the manpower in that particular process drastically and these resources can be used at some other place for more creative jobs.

- Improved compliance: RPA can take care of compliances which are rule based with few exceptions, well documented, require structured input, and repetitive in nature.

\subsection{COGNITIVE COMPLEXITY - FINDING PROCESS COMPLEXITY}

There are various methods to measure complexity of the process like number of activities, control flow complexity, nesting depth, Fan In/Fan Out etc., most of them being simple to measure modern complex processes. The control flow complexity (CFC) as defined by Cardoso is the number of decisions in the flow of control. These decisions generally are taken at the forks (split nodes), joins (merging notes) which causes parallel or rerouting or alternative routing in the flow of the process being executed. If we are defining complexity in terms of its difficulty to test the complete flow (i.e. how many test cases are needed to cover all scenarios of a particular model), the CFC metric performs an outstanding job. However, if we are analysing a model on the basis of its "difficulty to understand a model" then this method is not useful.

To overcome this challenge we have used cognitive complexity metric defined by Shao and Wang, which measures the cognitively and psychological complexity of a software. We will use the cognitive complexity matrix tailored for business process management by Gruhn and Laue.

Shao and Wang has defined a matrix on the basis of efforts needed to understand and interpret the software. This matrix assigns weight on the basis of conditions being fulfilled by the logical flow. Based on their studies, they came up with cognitive weights for various basic structures which forms complex structures and logics. This matrix was initially developed to calculate the complexity of software based application, but Gruhn and Laue further defined it in terms of business process management. Table 2 stated below contains the various control structures and their associated cognitive weight on the basis of difficulty to understand a process flow and its structure.

\begin{tabular}{|l|l|}
\hline BPM control structure & W \\
\hline Sequences of task in a process & 1 \\
\hline Exactly one of the two branch is executed from two Branches & 2 \\
\hline Exactly one of the branch is executed from more two branches & 3 \\
\hline A Fork and join concept; All the branches are executed from a fork & 4 \\
\hline One or more than one branch is executed from multiple branches & 7 \\
\hline Multiple tasks associated with a task (Subtasks present in a task) & 2 \\
\hline $\begin{array}{l}\text { More than one instance of a task (multiple instances either running } \\
\text { sequentially or parallelly) }\end{array}$ & 6 \\
\hline Cancellation of one task or subtask due to calling to another task & 1 \\
\hline $\begin{array}{l}\text { Cancellation of more than one task or subtasks due to call to another } \\
\text { task of process or another process }\end{array}$ & 2 or 3 \\
\hline
\end{tabular}

Table 2 - Cognitive complexity weightage

Using this matric we can calculate complexity of all processes by multiplying the count of each control structure with their weight and adding them all for a process, Once we have complexity for all the processes, we can do a relative positioning of these processes in a complexity vs value (in terms of saving caused due to automation of that process). This complexity vs value matrix has four quadrants. 


\subsection{CALCULATING COST SAVED BY RPA IMPLEMENTATION IN A PROCESSES}

There are various ways in which RPA automation helps in gaining benefits, few resulting in direct reflection into the balance sheet of the organization and few being non tangible. Here we will look at factors which helps in gaining direct benefit in terms of cost reduction.

To calculate the benefit three factors are considered; saving via reduction in manual hours, error reduction and gain in productivity of that process. The calculation can be understood by below table.

\begin{tabular}{|l|l|l|}
\hline \multicolumn{2}{|c|}{ A. Save via reduction in Manual Hours } \\
\hline A.1 & Average Total hours saved per process execution & 1 \\
\hline A.2 & Number of times process executes in a week & 10 \\
\hline A.3 & Total Hours saved in a year & 1040 \\
\hline A.4 & Per hour cost & $\$ 50$ \\
\hline A.5 & Annual saving due to manual hours reduction (A.3 * A.4) & $\$ 52,000$ \\
\hline \multicolumn{2}{|l|}{ B. Quality improvement resulting in error reduction } \\
\hline B.1 & Cost per error & $\$ 100$ \\
\hline B.2 & $\begin{array}{l}\text { Error occurrence rate (one error occurred every 'n' hours of } \\
\text { manual work) }\end{array}$ & 4 \\
\hline B.3 & Total number of error & 260 \\
\hline B.4 & Annual saving due to quality improvement (B.1 * B.3) & $\$ 26,000$ \\
\hline \multicolumn{2}{|c|}{ C. } & Saving due to gain in productivity \\
\hline C.1 & Increase in productivity due to hours saved (in \%) & $15 \%$ \\
\hline C.2 & Annual saving due to productivity gain (A.5* C.1) & $\$ 7,800$ \\
\hline Total saving per annum due to RPA implementation (A.5 + B.4 + C.2) & $\$ 85,800$ \\
\hline
\end{tabular}

Table 3 - Cost saving estimation calculation

\section{PRIORITIZING PROCESSES FOR AUTOMATION COMPLEXITY APPROACH}

We have used below step by step methodology to create the prioritizing groups for RPA automation.

Step 1. List down all the processes: In this step we will list down all the processes which are eligible for RPA automation. For this we will be using criteria defined in Table 1. This step will rule out all the processes which are not eligible for RPA automation.

Step 2. Calculate complexity of each Process: In this step we will be calculating process complexity of each process using weighted cognitive complexity matrix defined in table 2. This step will provide us with complexity of each process and the overall spread of the process complexity.

Step 3. Calculate the cost saving by RPA implementation: In this step we will calculate the overall cost which can be saved if the process is automated using RPA. For this we will use the calculation as per defined in table 3 .

Step 4. With the information obtained from $2^{\text {nd }}$ and $3^{\text {rd }}$ step, we will now create a matrix with $\mathrm{X}$ axis as complexity and $\mathrm{Y}$ axis as the value saved from the automation. We will map all the processes in the value vs complexity matrix as defined in Figure 1. In this matrix the axis are defined as below:

Value: Value of estimated profit realization post process automation using RPA Complexity: Complexity of the process as calculated in step 2 


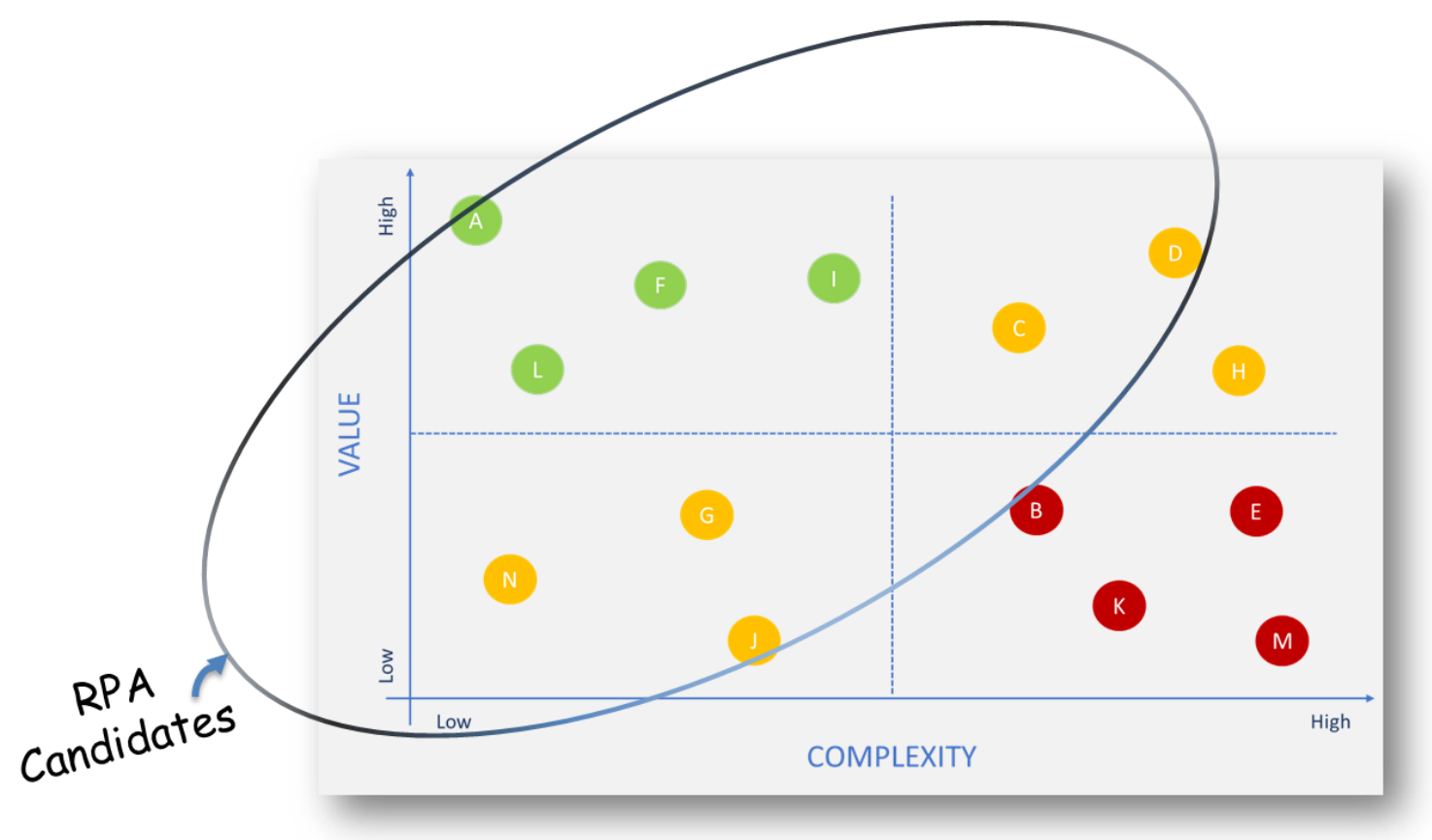

Figure 1 - Complexity vs Value matrix

The chart shows different processes of an organization and the benefits (in term of value) experience by the organization. Here, in this case, processes in first quadrant (processes denoted in green) are the easy go here, hence these should be picked first. Processes in second and fourth quadrant (denoted by yellow colour are either high complexity with high returns or low complexity with low returns). Hence these processes should be picked after all eligible processes in first quadrant are automated. Processes in third quadrant (denoted by red colour) are processes which have high complexity and low value. These processes should be least considered for automation considering ROI of the cost occurred for automation of these processes.

\section{SCOPE OF FURTHER RESEARCH}

This research paper focuses on creating project pipeline on the basis of only one factor i.e. process complexity vs the value added by automation. In further researches we may attempt to add other factors along with the complexity and hence we will come up with a full proof framework keeping in mind the factor that the pipeline for automation is highly optimum.

Further research can be conducted to improve the fitment of processes form relative to a more comprehensive one. Also, there is a further scope of research for the processes which are not able to provide good ROI. Researchers can further attempt to find out the methods to increase profit associated with such processes having high complexity.

\section{References}

[1] van der Aalst, W.M.P., Bichler, M. \& Heinzl, A. Robotic Process Automation. Bus Inf Syst Eng 60, 269-272 (2018). https://doi.org/10.1007/s12599-018-0542-4

[2] Hofmann, P., Samp, C. \& Urbach, N. Robotic process automation. Electron Markets 30, 99-106 (2020). https://doi.org/10.1007/s12525-019-00365-8

[3] Gruhn V., Laue R. (2007) Approaches for Business Process Model Complexity Metrics. In: Abramowicz W., Mayr H.C. (eds) Technologies for Business Information Systems. Springer, Dordrecht. https://doi.org/10.1007/1-4020-5634-6_2

[4] Beetz, R., \& Riedl, Y. Robotic Process Automation: Developing a Multi-Criteria Evaluation Model for the Selection of Automatable

Processes. AMCIS(2019). AIS Electronic Library (2019)

[5] V. Gruhn and R. Laue. Adopting the Cognitive Complexity Measure for Business Process Models. 5th IEEE International Conference on Cognitive Informatics, 
Beijing, 2006, pp. 236-241(2006). https://doi.org/10.1109/COGINF.2006.365702.

[6] Willcocks, L., Lacity, M., \& Craig, A. (2017). Robotic process automation: strategic transformation lever for global business services? Journal of Information Technology Teaching Cases, 7, 17-28. https://doi.org/10.1057/s41266-016-0016-9

[7] Asatiani, A., Penttinen, E. Turning robotic process automation into commercial success - Case OpusCapita (2016) Journal of Information Technology Teaching Cases, 6 (2), pp. 67-74. https://doi.org/10.1057/jittc.2016.5

[8] Aguirre, S., Rodriguez, A. Automation of a business process using robotic process automation (RPA): A case study (2017) Communications in Computer and Information Science, 742, pp. 65-71. https://doi.org/10.1007/978-3-319-66963-2_7

[9] Rowley, J., Slack, F. Conducting a literature review (2004) Management Research News, 27 (6), pp. 31-39. https://doi.org/10.1108/01409170410784185

[10] Hevner, A.R., March, S.T., Park, J., Ram, S. Design science in information systems research (2004) MIS Quarterly: Management Information Systems, 28 (1), pp. 75-105. https://doi.org/10.2307/25148625 